\title{
Correlation of TrpGly and GlyTrp Rotamer Structure with W7 and W10 UV Resonance Raman Modes and Fluorescence Emission Shifts
}

\author{
Azaria Solomon Eisenberg and Laura J. Juszczak \\ Department of Chemistry, Brooklyn College of the City University of New York, 2900 Bedford Avenue, Brooklyn, NY 11210, USA
}

Correspondence should be addressed to Laura J. Juszczak, ljuzak@brooklyn.cuny.edu

Received 30 March 2012; Accepted 4 May 2012

Academic Editor: Hieronim Jakubowski

Copyright (C) 2012 A. S. Eisenberg and L. J. Juszczak. This is an open access article distributed under the Creative Commons Attribution License, which permits unrestricted use, distribution, and reproduction in any medium, provided the original work is properly cited.

Tryptophyl glycine (TrpGly) and glycyl tryptophan (GlyTrp) dipeptides at pH 5.5 and pH 9.3 show a pattern of fluorescence emission shifts with the TrpGly zwitterion emission solely blue shifted. This pattern is matched by shifts in the UV resonance Raman (UVRR) W10 band position and the W7 Fermi doublet band ratio. Ab initio calculations show that the $1340 \mathrm{~cm}^{-1} \mathrm{band}$ of the W7 doublet is composed of three modes, two of which determine the W7 band ratios for the dipeptides. Molecular dynamics simulations show that the dipeptides take on two conformations: one with the peptide backbone extended; one with the backbone curled over the indole. The dihedral angle critical to these conformations is $\chi^{1}$ and takes on three discrete values. Only the TrpGly zwitterion spends an appreciable amount of time in the extended backbone conformation as this is stabilized by two hydrogen bonds with the terminal amine cation. According to a Stark effect model, a positive charge near the pyrrole keeps the ${ }^{1} \mathrm{~L}_{\mathrm{a}}$ transition at high energy, limiting fluorescence emission red shift, as observed for the TrpGly zwitterion. The hydrogen bond stabilized backbone provides a rationale for the $\mathrm{C}_{\text {methylene }}-\mathrm{C}_{\alpha}-\mathrm{C}_{\text {carbonyl }} \mathrm{W} 10$ symmetric stretch that is unique to the TrpGly zwitterion.

\section{Introduction}

Tryptophan fluorescence emission is a convenient, intrinsic probe of protein environment. Thus, it is used in a wide variety of studies ranging from protein folding [1-4], structure $[5,6]$, and stability $[2,7,8]$ to protein dynamics $[5,9]$ and ligand binding $[10,11]$. The tryptophan emission maximum displays wide variability, anywhere from $355 \mathrm{~nm}$ for solvent-exposed tryptophan to $303.5 \mathrm{~nm}$, for the "buried" Trp in the M97V mutant of Rhodospirillum rubrum dI transhydrogenase [12]. This association of solvent exposure with fluorescence emission maximum provides for a broad, qualitative assessment of tryptophan environment. However, a detailed molecular level understanding is lacking. Earlier work focused on classifying emission shift based on tryptophan exposure to water $[13,14]$. More recently, electrostatic contributions to tryptophan emission shifts were calculated for both the protein matrix and water [15-17]. In this internal Stark effect model, the widely used but simplistic association of red-shifted fluorescence emission with water exposure was not found. Moreover, the protein matrix plays a critical role in organizing water molecules, and so there is a subtle interplay between solvent and protein. The resultant single data point, the fluorescence emission maximum, does not suggest this complexity.

We apply vibrational spectroscopy to augment our understanding of Trp fluorescence emission shifts. UVRR spectra are sensitive to environment and are rich in wellresolved vibrational peaks that, unlike fluorescence, are specific to different parts of the indole ring. For example, the tryptophan UVRR W3 mode correlates with the $\chi^{2}$ dihedral angle between the indole ring and the peptide backbone [1820].

We focus our study on TrpX and XTrp dipeptides (where $X$ is any amino acid) in the zwitterionic and anionic states because TrpX zwitterions consistently display an $8-10 \mathrm{~nm}$, blue-shifted emission maximum relative to the other three dipeptide species [21]. These dipeptides are good models 
for tryptophan photophysics in proteins because the fluorescence properties of the set of rotamers for a specific dipeptide can be varied through adjustment of solution conditions $[22,23]$.

In this study-the first in a series-we begin with the simplest Trp dipeptides, TrpGly and GlyTrp in their zwitterionic and anionic forms. Observed changes in the UVRR spectra of each are coupled with ab initio structural calculations and nanosecond molecular dynamics (MD) simulations to provide insight into the molecular level determinants of Trp fluorescence emission. Our results show that the W7 and W10 modes are sensitive to both primary structure and charge state. The W10 mode Raman shift for each dipeptide species correlates with its fluorescence emission maximum. The W7 mode Fermi doublet peak intensity ratio, $I\left(1360 \mathrm{~cm}^{-1}\right) / I\left(1340 \mathrm{~cm}^{-1}\right)[24,25]$, is also found to correlate with the tryptophan dipeptide fluorescence emission maxima in the two charged states. Thus, our study reveals tryptophan molecular vibrations that are common to tryptophan in a red-versus-blue emission state and relates this experimental information on specific rotamers to simulated molecular configuration.

\section{Methods}

Tryptophan dipeptides were purchased from Research Plus Inc. (Barnegat, NJ) and used as provided. For UVRR spectroscopy, where the signal cross-section is low and therefore relatively high tryptophan concentrations are required, all dipeptides were dissolved to a concentration of $0.3 \mathrm{mM}$. Dipeptide solubility is not an issue at this concentration as solutions of $1 \mathrm{mg} / \mathrm{mL}(3.6 \mathrm{mM})$ were prepared as stock solutions without issue. We do not therefore expect any oligomerization effects at $0.3 \mathrm{mM}$ peptide concentration. The buffer was $1 \mathrm{mM}$ sodium phosphate buffer at $\mathrm{pH} 5.5$ or 9.3 to reproduce the solution conditions (and thus the fluorescence emission results) employed by Chen et al. [21].

\subsection{Fluorescence Emission Spectroscopy. Fluorescence spectra} were acquired on a PTI QM-4/206 SE spectrofluorometer (PTI, Birmingham, NJ) with an excitation of $279 \mathrm{~nm}$ and 1 second acquisition time for each $\mathrm{nm}$ step with rightangle detection of fluorescence. For emission, all dipeptide solutions were diluted to a concentration of $0.01 \mathrm{mM}$ to avoid emission attenuation via inner filter effects. Within the $0.01-0.3 \mathrm{mM}$ concentration range used in the experiments, we do not expect any significant oligomerization effects, and so the results for all measurements are consistent.

2.2. UVRR Spectroscopy. The laser source for $228.9 \mathrm{~nm}$ excitation was a Cambridge Laser 85-SHG continuous wave, intracavity frequency-doubled (via a beta barium borate crystal) instrument (Cambridge Laser, Fremont, CA). UV light was dispersed via a UV fused silica Pellin-Broca prism (Thorlabs, Newton, NJ) in order to spatially separate out plasma emission lines [26], which were subsequently blocked by a pinhole. The laser beam was directed and minimally focused onto the sample in a backscattering configuration.
Scattered Raman signal was collected by an antireflection(AR-) coated triplet collection lens (CVI Laser, LLC, Albuquerque, NM) and focused with a $2^{\prime \prime}$ diameter focal length matched lens on the entrance slit of the monochromator. Additionally, the Raman signal is scrambled immediately before entrance into the monochromator via an AR-coated depolarizer (Optics for Research, West Caldwell, NJ).

The Raman signal was dispersed by a Horiba/Jobin Yvon model $1000 \mathrm{M}$ single-grating (3600 grooves $/ \mathrm{mm}$, resolution $2 \mathrm{~cm}^{-1}$ ) monochromator (Edison, $\mathrm{NJ}$ ) and collected by a liquid nitrogen-cooled Symphony charge-coupled device camera (Horiba/Jobin Yvon, Edison, NJ). The monochromatorCCD camera resolution is $0.1 \AA\left(2 \mathrm{~cm}^{-1}\right)$ as determined with a mercury-argon calibration lamp (Oriel Instruments, Stratford, CT). The UV power at the sample is $1 \mathrm{~mW}$. The monochromator slit width is set to 150 microns for all measurements.

Typically, $0.5 \mathrm{~mL}$ of a solution sample in a $1 \mathrm{~cm}$ diameter quartz NMR tube is spun using a precision Raman spinner (Princeton Photonics Inc., Princeton, NJ) and rastered using a small DC motor mounted on a lab-assembled stage to prevent UV-induced sample damage.

The digitalized signal is saved on a desktop computer using the Synergy software program, an Origin 7.5-based program (OriginLab Corp., Northampton, MA) provided by Horiba/Jobin Yvon. For the serial acquisitions, the first is compared to those taken at the end. If spectral changes are found, end acquisitions are rejected. Raman shifts are calibrated with peaks from toluene and ethanol. The Origin 7.5 application was used for all spectral processing and manipulation.

\section{Computational Methods}

3.1. DFT PCM Modeling. Calculations on all species were executed on a single-processor Windows desktop computer using Gaussian 09 software [27] with the B3LYP method and the $6-311(\mathrm{~d}, \mathrm{p})$ basis set [28]. Most of the relevant calculations used the polarizability continuum model (PCM) in order to include the effects of a water solvent. Gas-phase calculations of the zwitterionic forms are not possible as energy minimization attempts on the zwitterion result in a charge transfer and dissociation of the molecule; neutral species are used instead. Vibrational frequencies were scaled by a factor of 0.9614 [28]. Discrepancies between calculated and observed frequencies were accepted up to $\pm 34 \mathrm{~cm}^{-1}$ as seen in the literature [28]. Each frequency was given a $20 \mathrm{~cm}^{-1}$ broadening to more accurately reflect the true spectra.

3.2. Molecular Dynamics. Gromacs simulations [29] were done on TrpGly and GlyTrp dipeptides, each in the zwitterionic and anionic state in a water solvent cubic box with a minimum of $1 \mathrm{~nm}$ distance between the box wall and any atom of the peptide. The suggested TIP-4p water model was used in the simulations, with $\sim 1000$ solvent molecules in each simulation. The optimized potentials for liquid simulations all atom (OPLSA) force field was used in 
all cases. A steepest-descent algorithm was used to minimize the energy of the structure before any simulations were performed. The simulations all took place at $298 \mathrm{~K}$ and used periodic boundary conditions with a modified Berendsen thermostat. For smoothness of viewing, the time step was chosen as 0.5 femtoseconds. Due to the subnanosecond relaxation time for a system of this size, we have found 2 ns to be a sufficient time for the length of most of our simulations [30-32], though to ensure clarity of some results, we have extended the simulations up to $10 \mathrm{~ns}$. A complete list of all parameters is available upon request. Analysis of the molecular dynamics trajectories was done using freeware, gOpenMol [33] (CSC-IT, Center for Science, Ltd., Finland).

3.3. Molecular Imaging. The molecular images in Figure 2 were modeled with the freeware programs, ChemSketch and 3D Viewer (ACD/Labs, Advanced Chemistry Development, Inc., Toronto, Canada). The molecular images in Figure 9 were created with the Chimera software, beta version 1 built 1951 2004/05/11 (University of California, San Francisco, CA).

\section{Results}

UVRR spectra for the four Trp dipeptides are given in Figure 1(a) and (c). The UVRR spectrum for aqueous Ltryptophan is given in Figure 1(b) for comparison. These results reveal that intense peaks, such as W16 and W18, show little or no change in Raman shift with $\mathrm{pH}$ or amino acid order. In particular, the W3 band position, shown to track with the tryptophan dihedral angle, $\chi^{2}$ [18-20], is at $1551 \mathrm{~cm}^{-1}$ for all dipeptide species. Dihedral angles are defined in Figure 2. The data in Figure 1 show that the spectral features of two other modes, W10 $\left(1335-42 \mathrm{~cm}^{-1}\right)$ and the W7 Fermi doublet (ca. $1340 \mathrm{~cm}^{-1}$ and $1360 \mathrm{~cm}^{-1}$ ), change with both $\mathrm{pH}$ and tryptophan position. Gaining a molecular level understanding of these two modes is the focus of the remainder of the paper.

\subsection{Wavenumber Position of W10 Peaks Track with Emission} Maxima for Tryptophan Dipeptides. The normalized fluorescence emission spectra for all four tryptophan dipeptide species are given in Figure 3(a). The TrpGly zwitterion has the highest energy fluorescence emission maximum at $347 \mathrm{~nm}$, (Figure 3(a)). The emission maxima of the remaining three dipeptide species are shifted to lower energy, $357 \mathrm{~nm}$. Emission difference spectra between the spectrum for the TrpGly zwitterion and the spectra for all other dipeptide species are given in Figure 4. These difference spectra are similar; each is characterized by a positive band centered at ca. $328 \mathrm{~nm}$ and a negative peak at $380 \mathrm{~nm}$. The results suggest a distinct set of conformers for the TrpGly zwitterion that is responsible for the blue-shifted fluorescence emission.

The W10 peaks for the four tryptophan dipeptide species (Figure 3(b)) parallel the trend observed in the fluorescence emission spectra (Figure 3(a)). The magnitudes of the shifts are also in parallel (Table 1). As for the set of fluorescence emission spectra, the TrpGly zwitterion is the species with

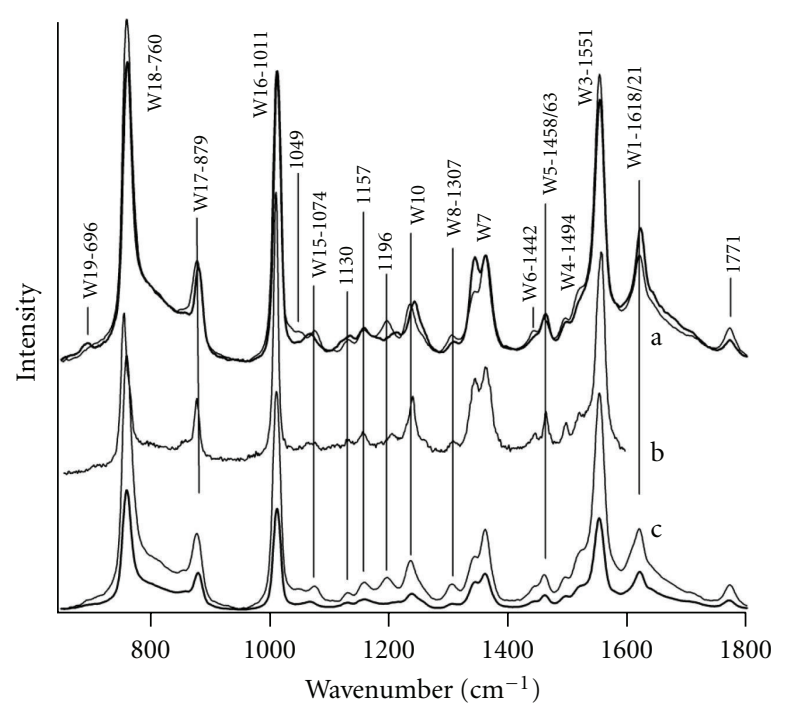

FIGURE 1: UVRR (229 nm excitation) results for tryptophan and glycine dipeptides in the anionic and zwitterionic state from 600$1800 \mathrm{~cm}^{-1}$ : (a) TrpGly (bold line) and GlyTrp (solid line) at pH 5.5, (b) L-tryptophan in deionized water, and (c) TrpGly (bold line) and GlyTrp (solid line) at $\mathrm{pH}$ 9.3.

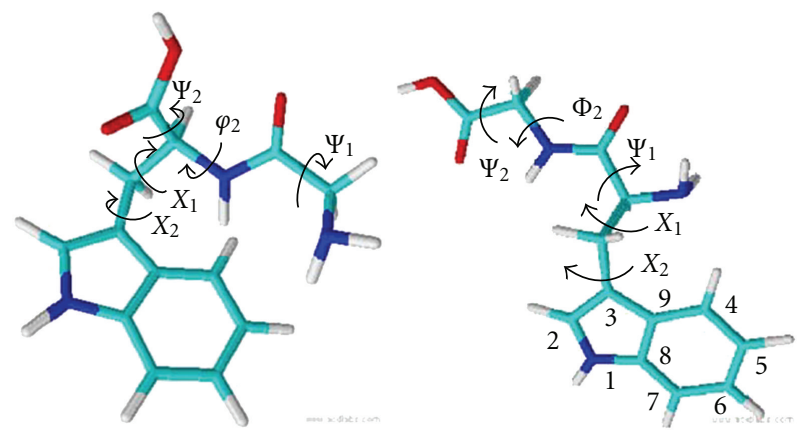

FIGURE 2: Molecular structures with dihedral angles, $\chi^{1}, \chi^{2}, \psi^{1}, \varphi^{2}$, and $\psi^{2}$, defined for GlyTrp, left, and TrpGly, right. The indole ring atoms are enumerated on the TrpGly structure for reference.

highest energy W10 peak $\left(1243 \mathrm{~cm}^{-1}\right)$. A similar pattern of W10 band shifts has been found for dipeptides of tryptophan with leucine or glutamine, as summarized in Table 2. The fluorescence emission maxima for the leucine and glutamine dipeptide species are analogous to those for the tryptophan/glycine dipeptides given here (data not shown) and to those given in Chen et al. [21]. The observation of these spectroscopic trends for additional dipeptides eliminates the possibility that the W10 pattern of peaks is unique to dipeptides with glycine.

4.2. The W7 Fermi Doublet Intensity Ratio, $I\left(1360 \mathrm{~cm}^{-1}\right) /$ I $\left(1340 \mathrm{~cm}^{-1}\right)$, Tracks with Fluorescence Emission Maxima for Tryptophan Dipeptides. The W7 Fermi doublet band intensity ratio has previously been identified as a marker for indole ring hydrophobicity, with an $I\left(\sim 1360 \mathrm{~cm}^{-1}\right) / I\left(\sim 1340 \mathrm{~cm}^{-1}\right)$ ratio $>1$ for indoles in solution with aromatic and saturated hydrocarbon solvents under nonresonant Raman conditions 


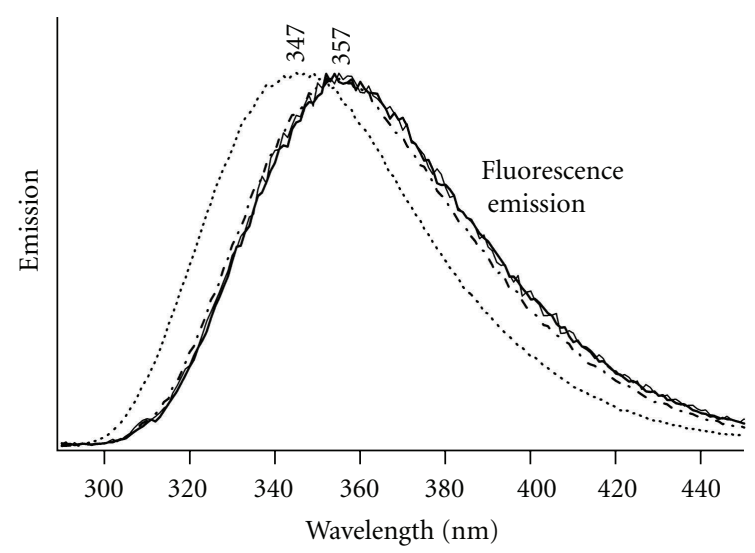

(a)

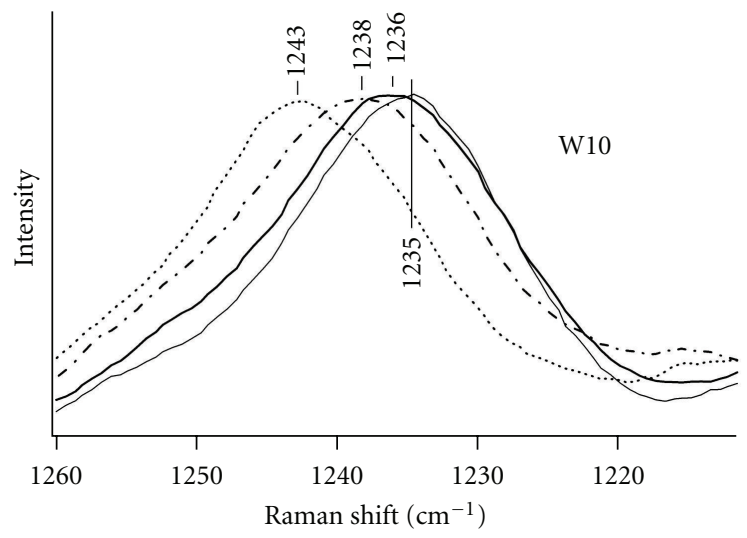

(b)

Figure 3: Spectra for TrpGly at pH 5.5 (dotted line) and pH 9.3 (dot-dash line), and GlyTrp at pH 5.5 (solid line) and pH 9.3 (bold line). (a) Fluorescence emission spectra, $279 \mathrm{~nm}$ excitation, $2 \mathrm{~nm}$ slits, $1 \mathrm{sec}$ acquisition time, and $1 \mathrm{~nm}$ step size. The GlyTrp emission spectra are normalized to those for TrpGly. (b) UVRR W10 band.

TAble 1: Fluorescence emission maxima, experimental and calculated W10 band peaks and W7 Fermi doublet band ratio, $I\left(1360 \mathrm{~cm}^{-1}\right) / I\left(1340 \mathrm{~cm}^{-1}\right)$, for GW and WG dipeptides at $\mathrm{pH} 5.5$ and 9.3. Parenthetical values are for shifts relative to values for the WG zwitterion species.

\begin{tabular}{lcccc}
\hline Peptide, $\mathrm{pH}$ & $\begin{array}{c}\text { Experimental W10 Raman } \\
\text { Shift }\left(\mathrm{cm}^{-1}\right)\end{array}$ & $\begin{array}{c}\text { Calculated W10 Raman Shift } \\
\left(\mathrm{cm}^{-1}\right)\end{array}$ & $\begin{array}{c}\text { W7 } \\
I\left(1360 \mathrm{~cm}^{-1}\right) / I\left(1340 \mathrm{~cm}^{-1}\right)\end{array}$ & $\begin{array}{c}\text { Fluorescence emission } \\
(\mathrm{nm})\end{array}$ \\
\hline WG, 5.5 & 1242 & 1271 & 1.0 & 347 \\
WG, 9.3 & $1239(-3)$ & $1267(-4)$ & 1.4 & $355(+8)$ \\
GW, 5.5 & $1235(-7)$ & $1268(-3)$ & 1.6 & $357(+10)$ \\
GW, 9.3 & $1236(-6)$ & $1262(-9)$ & 1.6 & $357(+10)$ \\
\hline
\end{tabular}

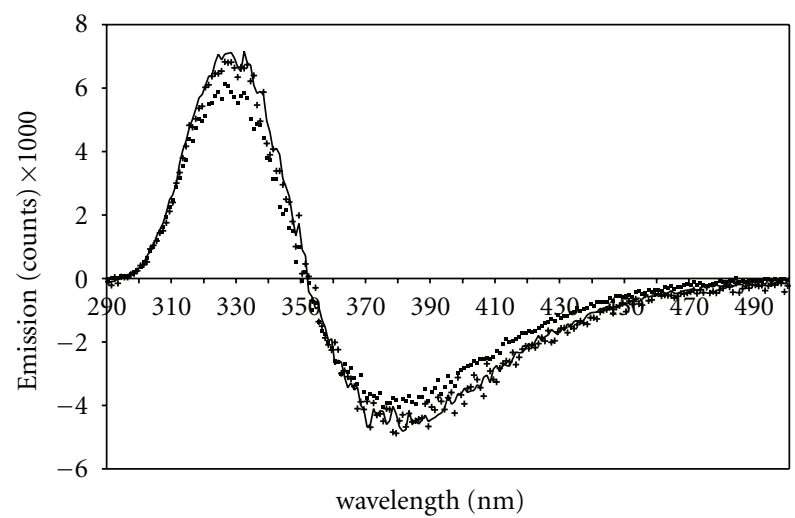

FIGURE 4: Fluorescence difference emission spectra (all spectra normalized at their emission maxima) between dipeptides: WG $\mathrm{pH}$ 5.5 minus: WG pH 9.3 (solid line), GW pH 5.5 (cross points), GW pH9.3 (square points). Peaks are located at 329 and $380 \mathrm{~nm}$.

[24]. This relationship has been applied under resonance Raman conditions as well [25, 34-39]. Additionally, large changes in the Fermi doublet band intensity ratio have been observed at tryptophan derivative $\mathrm{pK}_{\mathrm{a}} \mathrm{s}$; a ratio value $\sim 1$ is found for tryptophan at $\mathrm{pH} 6.15$, and $>1$ at $\mathrm{pH} 13$ under nonresonant Raman conditions [24]. We obtain values greater than unity for the Fermi doublet intensity ratios for

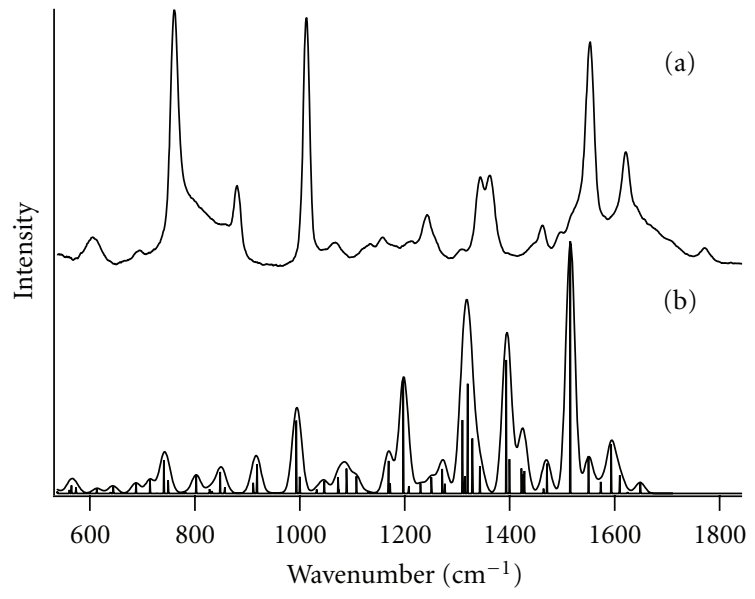

FIGURE 5: (a) Experimental UVRR spectrum for TrpGly zwitterion. (b) Calculated UVRR spectrum for TrpGly zwitterion, B3LYP DFT functional with $6-31++\mathrm{G}^{* *}$ basis set, 0.9635 scaling factor (vertical lines), and with $20 \mathrm{~cm}^{-1}$ peak broadening (solid, continuous line).

three out of four tryptophan dipeptide species, as given in Table 1. The W7 ratio for the TrpGly zwitterion is again the exception. This trend is observed for the W7 intensity ratios of tryptophan dipeptides of leucine and glutamine as well (data not shown). 
TABLE 2: UVRR W10 peaks $(1 / \mathrm{cm})$ for Trp dipeptides at $\mathrm{pH} 5.5$ and 9.3.

\begin{tabular}{lcc}
\hline Dipeptide & \multicolumn{2}{c}{ W10 wavenumber $(1 / \mathrm{cm})$} \\
& pH 5.5 & pH 9.3 \\
\hline GluTrp & 1235 & 1236 \\
TrpGlu & 1241 & 1238 \\
LeuTrp & 1237 & 1237 \\
TrpLeu & 1240 & 1237 \\
\hline
\end{tabular}

4.3. Theoretical Calculations. Theoretically derived UVRR spectra provide the molecular modes associated with individual vibrations and thus aid in understanding of band changes for different dipeptide species. Calculated UVRR results for the TrpGly zwitterion along with a $20 \mathrm{~cm}^{-1}$ broadened representation are shown in Figure 5(b). Experimental UVRR results for the TrpGly zwitterion are given again in Figure 5(a) to illustrate relative band positions. We note that calculated bands at $1320 \mathrm{~cm}^{-1}$ and $1395 \mathrm{~cm}^{-1}$ (Figure 5(b)) are within the accepted $\pm 34 \mathrm{~cm}^{-1}$ error range for band assignment to experimental peaks at $1344 \mathrm{~cm}^{-1}$ and $1362 \mathrm{~cm}^{-1}$ (Figure 5(a)), as given in the literature [28]. Comparison of calculated and experimental W7 and W10 modes is detailed below. We note that other groups have found more than one W7 fundamental in their calculations [20, 40-43]. A multiplet of bands- three to four-in the W7 region for tryptophan cation, zwitterion, and anion under nonresonance Raman conditions and in the presence of water and heavy water has also been observed experimentally [24].

4.4. Calculated W10 Mode. DFT PCM modeling yields bands at $1262-1271 \mathrm{~cm}^{-1}$ that can be assigned to the W10 mode for the Trp dipeptide species (Table 1). The calculated W10 band shifts track with the experimental W10 shifts for all dipeptide species with the exception of the GlyTrp anion. Calculated vibrational movements for W10 are shown in Figure 6, and details of the atomic movements are included. The atomic displacements for the indole residue agree with those published elsewhere for 3-methylindole [44]. The W10 vibrational modes for all dipeptide species are primarily ring breathing modes centered on the pyrrole ring. One of the noteworthy vibrational differences between the W10 modes for the different dipeptide species is the tryptophan $\mathrm{C}_{\text {methylene }}-\mathrm{C}_{\alpha}-\mathrm{C}_{\text {carbonyl }}$ symmetric stretch that is unique to the TrpGly zwitterion.

4.5. Calculated W7 Modes. The calculated spectra of the TrpGly and GlyTrp dipeptide species reflect the intensity changes that occur in the W7 doublet. It is imperative to understand that we are not matching calculated nonresonance Raman band intensities to resonance Raman experimental peaks. Instead, we are assigning individual calculated modes to experimental peaks. In some cases, more than one calculated mode or frequency is assigned to the same peak. The calculated bands that relate to the experimental W7 $1362 \mathrm{~cm}^{-1}$ and $1344 \mathrm{~cm}^{-1}$ peaks are found at $1395 \mathrm{~cm}^{-1}$

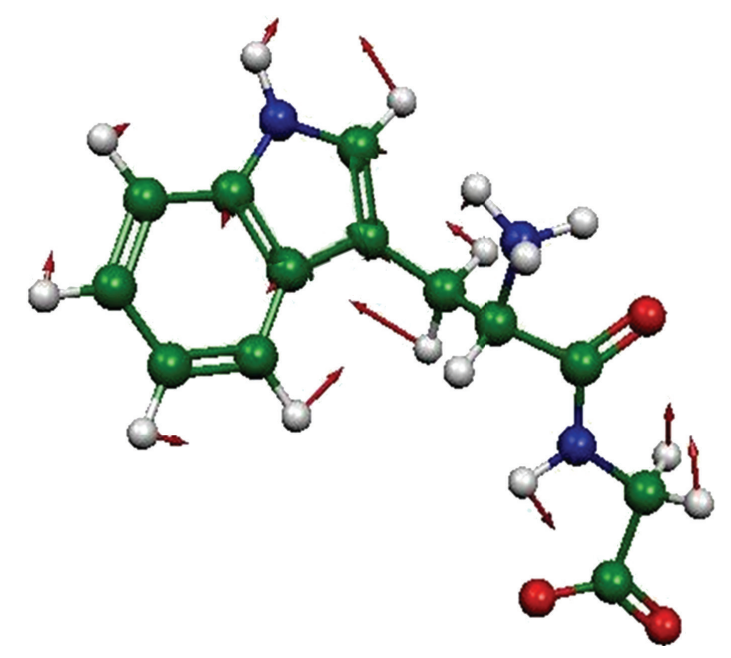

Figure 6: TrpGly zwitterion calculated vibrations at $1271 \mathrm{~cm}^{-1}$. Prominent motions for all dipeptide species include a C8-N1C2 symmetric stretch synchronous with a C3-C9 stretch. A $\mathrm{C}_{\text {methylene }}-\mathrm{C}_{\alpha}-\mathrm{C}_{\text {carbonyl }}$ symmetric stretch is found only for the TrpGly zwitterion. Hydrogen bending motions are found on C2, C4-7, and $\mathrm{C}_{\text {methylene. }}$.

and $1320 \mathrm{~cm}^{-1}$, respectively (Figure $5(\mathrm{~b})$ ). For clarity in discussion, we shall hereafter refer to the experimental W7 bands as W7a $\left(1344 \mathrm{~cm}^{-1}\right)$ and W7b $\left(1362 \mathrm{~cm}^{-1}\right)$. The calculations predict that the W7a peak, which is more intense for the TrpGly zwitterion, is composed of more than one vibrational frequency, while the W7b band is mostly associated with a single vibration. The movements of the W7b vibration on the indole ring are the same for all the species and consist of asymmetric stretches spread over the indole ring and attached methyl group, as shown in Figure S1 (See Figure S1 in Supplementary Material available at doi:10.1155/2012/735076). The similarity of the calculated vibrations for all the dipeptide species suggests that the W7b peak is not responsible for the observed W7 intensity ratio changes.

The calculated $1320 \mathrm{~cm}^{-1}$ band, corresponding to $\mathrm{W} 7 \mathrm{a}$, is composed of three vibrational energy transitions at $1310 \mathrm{~cm}^{-1}, 1320 \mathrm{~cm}^{-1}$, and $1329 \mathrm{~cm}^{-1}$. The vibrations for these three transitions in the TrpGly zwitterion are illustrated in Figures S2-S4. Specific atom motions common to all dipeptide species are given in caption. The $1320 \mathrm{~cm}^{-1}$ and $1329 \mathrm{~cm}^{-1}$ vibrations are similar for all dipeptide species. However, the $1310 \mathrm{~cm}^{-1}$ vibration does not occur in the TrpGly anion or the GlyTrp zwitterion calculated spectra. The lack of this vibration causes the calculated $1320 \mathrm{~cm}^{-1}$ band, which is the sum of the three transitions, to have a lower intensity for the TrpGly anion or the GlyTrp zwitterion (data not shown) and thus correctly predicts the lowered intensity of their W7a band in the experimental UVRR spectra. Even the GlyTrp anion, for which the $1320 \mathrm{~cm}^{-1}$ calculated band has only a slightly lowered intensity, does not have all the transitions. The calculations therefore provide an explanation for the observed lower intensity of the W7a band for both anionic species and the GlyTrp zwitterion (Table 1). 

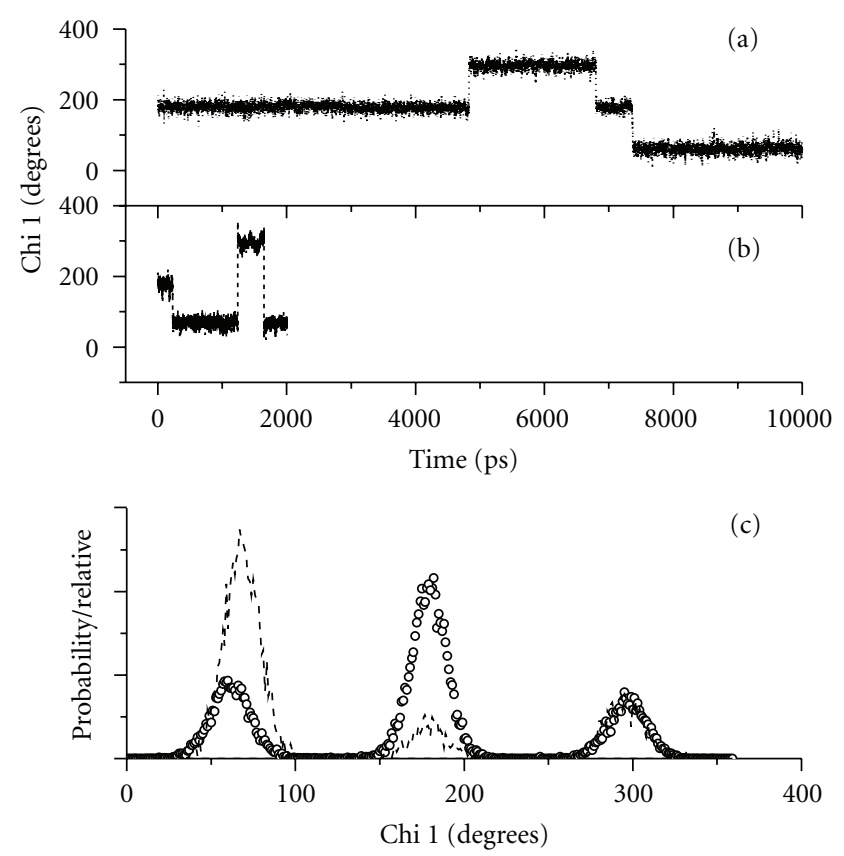

Figure 7: $\chi^{1}$ molecular dynamic trajectories and probabilities for TrpGly species: (a) zwitterionic, $10 \mathrm{~ns}$ duration, (b) anionic, $2 \mathrm{~ns}$ duration. (c) Corresponding $\chi^{1}$ probability for TrpGly zwitterion (dotted line) and anion (dashed line).

4.6. Molecular Dynamics Simulations. We have carried out simulations of the zwitterionic and anionic TrpGly and GlyTrp dipeptide conformations in a cavity filled with $\sim 1000$ water molecules for a period ranging from 2 to $10 \mathrm{~ns}$ in order to ensure that all conformational angles were sampled. Measurements of the $\chi^{1}, \chi^{2}, \psi^{1}, \varphi^{2}$, and $\psi^{2}$ angles, illustrated in Figure 2, were taken throughout the trajectory.

Two conformations predominate for all four species, and these are almost entirely dictated by the $\chi^{1}$ angle. For all the species, there are only 3 ranges for the $\chi^{1}$ angle: $60 \pm 30^{\circ}$, $180 \pm 25^{\circ}$, and $300 \pm 35^{\circ}$, as illustrated in the $\chi^{1}$ probabilities in Figures 7 (c) and 8(c). MD trajectories for the TrpGly species are given in Figure $7(\mathrm{a})$ and (b) while those for GlyTrp species are given in Figure 8(a) and (b). These MD trajectories show that the conformers spend an appreciable amount of time at any one of the three $\chi^{1}$ angles before switching "instantaneously" to another angle.

When the $\chi^{1}$ angle is in either of the last two ranges, given above, the molecule is in its backbone "stretchedout" conformation, as illustrated in Figure 9(a). When the $\chi^{1}$ angle is close to $60^{\circ}$, however, the molecule is in its backbone "folded" conformation, as illustrated in Figure 9(b). A set of dihedral angles $\left(\chi^{1}, \chi^{2}, \psi^{1}, \varphi^{2}, \psi^{2}\right)$ for the calculated, lowenergy conformers of the tryptophan dipeptide species is given in Table S1. Note that the values of the dihedral angle, $\chi^{2}$, are similar-ranging from $80^{\circ}$ to $110^{\circ}$. These calculated $\chi^{2}$ angles are in rough agreement with the $95^{\circ}$ angle predicted by the W3 position at $1551 \mathrm{~cm}^{-1}$ [20].
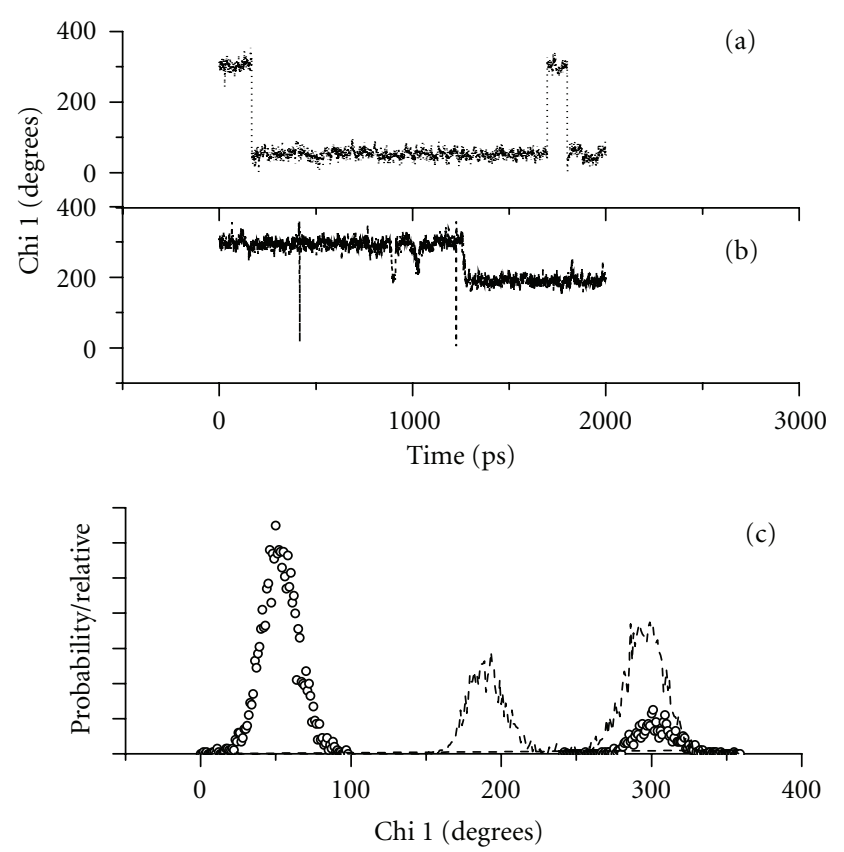

FIGURE 8: $\chi^{1}$ molecular dynamic trajectories and probabilities for GlyTrp species: (a) zwitterionic, $10 \mathrm{~ns}$ duration, (b) anionic, $2 \mathrm{~ns}$ duration. (c) Corresponding $\chi^{1}$ probability for GlyTrp zwitterion (dotted line) and anion (dashed line).

\section{Discussion}

In the following paragraphs, we will describe the quantum mechanically determined low-energy tryptophan dipeptide conformers and discuss their conformational motions as determined from the molecular dynamics simulations. Afterwards, the spectral consequences of the dominant, extended conformation of the TrpGly zwitterion, $\mathrm{pH} 5.5$ species, which places the terminal amine cation within hydrogen bonding distance of a pyrrole ring carbon, will be discussed.

5.1. Two Conformers for the TrpGly Zwitterion. The TrpGly zwitterion spends proportionally greater time in the extended backbone conformation as shown by the $\chi^{1}$ probability plot in Figure 7 (c), dotted line. The extended conformation is represented by the sum of $\chi^{1}$ probabilities at $180^{\circ}$ and $300^{\circ}$. The simulations show that the TrpGly anion (Figure $7(\mathrm{c})$, dashed line) and the GlyTrp zwitterion (Figure 8(c), dotted line) spend some time in the stretched conformation, but neither spends as much time in the stretched conformation as the TrpGly zwitterion. The energy-minimized structures for both TrpGly zwitterion conformations are illustrated in Figures 9(a) and 9(b). In one conformer, the peptide backbone is extended (Figure 9(a)), and the N-terminal amine cation is within hydrogen bonding distance $(1.96 \AA)$ of the oxygen of the peptide bond carbonyl. Additionally, a second hydrogen on the terminal amine cation is $2.44 \AA$ from $\mathrm{C}_{3}$ of the pyrrole ring. The short distance-2.44 $\AA$ - between the amine proton and the $\mathrm{C}_{3}$ of the indole ring does not allow for an intervening, hydrogen bonded water molecule. This close approach of an amine proton to the indole ring 


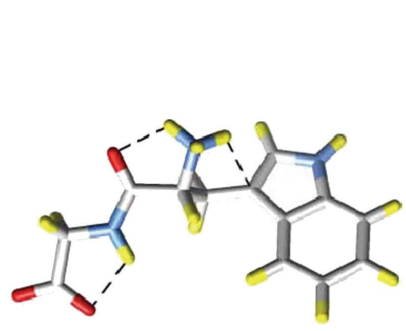

(a)

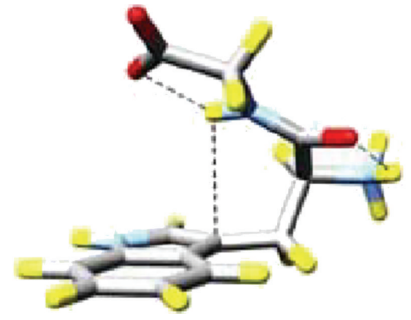

(b)

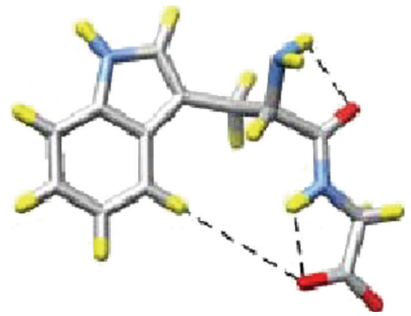

(c)

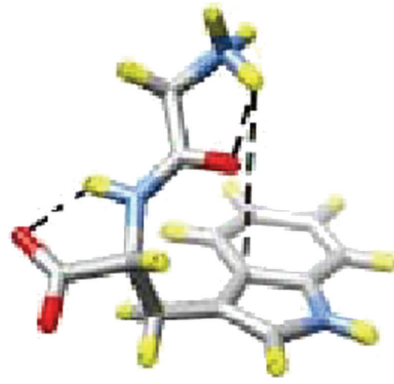

(d)

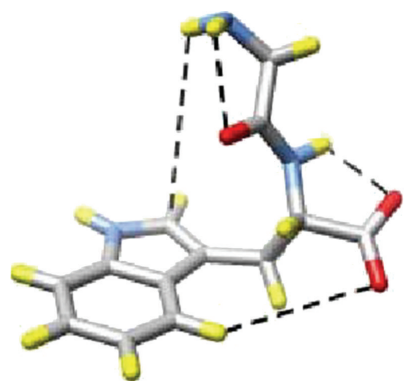

(e)

FIGURE 9: Lowest-energy molecular conformers for tryptophan dipeptides in the zwitterion and anionic forms. (a) TrpGly, pH 5.5, stretchedout backbone conformer, (b) folded backbone conformer, (c) TrpGly, pH 9.3, (d) GlyTrp, pH 5.5, and (e) GlyTrp, pH 9.3. Atoms are color coded as follows: $\mathrm{N}$, blue; $\mathrm{O}$, red; $\mathrm{H}$, yellow; $\mathrm{C}$, grey. Dashed lines indicate electrostatic interactions discussed in the text.

is unique to this conformer of the TrpGly zwitterion and to these TrpGly/GlyTrp dipeptides.

The second TrpGly zwitterion conformer, illustrated in Figure 9(b), is characterized by a backbone which folds back over the indole ring. This conformer has a slightly higher energy than the stretched conformer. There are two intrabackbone hydrogen bonds: between the terminal amine cation and the adjacent peptide carbonyl (1.95 $\AA$ ) and between the C-terminal carboxyl anion and the peptide amine $(2.02 \AA)$. The peptide amine hydrogen is positioned $2.92 \AA$ above the indole $C_{3}$, and the carboxylate oxyanion is $4.03 \AA$ above the indole $\mathrm{C}_{8}$, allowing for an intervening water molecule and hydrogen bonding. Significantly, the terminal amine cation is positioned well away from the indole ring for this conformer.

5.2. The TrpGly Anion Lacks Amine Interaction with the Indole Ring. The TrpGly anion spends appreciable time in a conformer where $\chi^{1} \sim 60^{\circ}$ (Figure 7(c), dashed line). A representative conformer, where the backbone is folded, is shown in Figure 9(c). This conformer is characterized by two intrabackbone hydrogen bonds: between the N-terminal amine hydrogen and peptide bond carbonyl oxygen (2.40 $\AA$ ) and the peptide bond amine hydrogen and the C-terminal carboxylate $(2.06 \AA)$. The latter hydrogen bond provides for a folding back of the peptide backbone such that the Cterminal carboxylate partakes in an edge-on, $\mathrm{CH}-\mathrm{O}$ weak interaction with the benzyl ring $C_{4}(3.89 \AA)[45,46]$. We note that the hydrogens of the terminal, neutral amine are turned away from the indole ring.
5.3. The Terminal Amine Cation of the GlyTrp Zwitterion Is Positioned above the Indole Ring. When the amino acid positions are switched, a folded-back peptide backbone provides for optimal positioning of the amine cation above the indole ring but not in close proximity. The molecular conformer for the GlyTrp zwitterion is shown in Figure 9 (d). This species spends most of its simulation time in the conformation where $\chi^{1} \sim 60^{\circ}$ (Figure 8(c), dotted line). The distance between one hydrogen of the amine cation and $\mathrm{C}_{9}$ of the indole ring is $4.80 \AA$, well within the $6 \AA$ cutoff for cation$\pi$ interactions [47]. A chain of electrostatic interactionsfrom amine hydrogen to water molecule to indole ring $\pi$ electrons-is envisioned. The same hydrogen of the amine cation is also within hydrogen bonding distance $(1.84 \AA)$ of the peptide carbonyl oxygen. This hydrogen bond orients the amine proton toward the indole $\pi$ electrons.

5.4. The Terminal Amine of the GlyTrp Anion Is Well above the Indole Plane. The conformers for the GlyTrp anion are not readily described with just the $\chi^{1}$ dihedral angle. This is due to the unusual variability of the $\chi^{2}$ angle that the GlyTrp anion exhibits. Whereas the other three species' $\chi^{2}$ angle only varies between $60^{\circ}$ and $100^{\circ}$, the GlyTrp anion $\chi^{2}$ angle varies between $50^{\circ}$ and $300^{\circ}$ and, interestingly enough, even spends a small but significant amount of time with $\chi^{2} \sim 180^{\circ}$.

As for the GlyTrp zwitterion, the backbone of the GlyTrp anion, shown in Figure 9(e), folds back towards the indole ring even though the species spends no time with $\chi^{1} \sim 60^{\circ}$ (Figure 8(c), dashed line). The curled backbone structure (Figure $9(\mathrm{e})$ ) is stabilized by two hydrogen bonds, a terminal 
$\mathrm{NH}$ to $\mathrm{O}=\mathrm{C}$ peptide $(2.46 \AA)$ and a terminal $\mathrm{C}=\mathrm{O}$ to $\mathrm{HN}$ peptide $(2.10 \AA)$ hydrogen bond. The terminal amine is also positioned above the indole plane, with an interatomic distance of $4.99 \AA$ between one amine hydrogen and $\mathrm{C}_{2}$ of the indole. The terminal oxyanion is $4.03 \AA$ from the $\mathrm{C}_{4}$ hydrogen.

5.5. Spectral Consequences of the Amine Cation-Pyrrole Hydrogen Bond in the TrpGly Zwitterion. The most striking distinction between the quantum mechanically determined low-energy tryptophan dipeptide conformers given in Figure 9 is the stretched-out conformation adapted primarily by the TrpGly zwitterion (Figure 9(a)). The resultant close approach $(2.44 \AA)$ of one terminal amine hydrogen to the pyrrole ring $\mathrm{C}_{3}$ can account for the relatively blue-shifted fluorescence emission maximum $(347 \mathrm{~nm})$ of the TrpGly zwitterion, according to an internal Stark effect model [16, 17]. The hybrid quantum mechanical-molecular dynamics studies of Callis and coworkers $[16,17]$ predict that a positive charge placed near to the pyrrole half of the indole or a negative charge near the benzyl ring will result in an emission blue shift. Oppositely placed charges are predicted to result in an emission red shift. A potential difference across the long axis of the indole ring determines the emission wavelength, and orientation of the charge relative to the ring is critical. Just in terms of order of magnitude, hydrogen bonding between a water molecule and the $\pi$-electrons of the benzyl ring of 3-methyl indole was calculated to create a red shift of $15 \mathrm{~nm}$ [17], which is of comparable magnitude to the $10 \mathrm{~nm}$ blue shift observed for TrpGly zwitterion here.

DFT-PCM calculation of the W10 mode positions for the dipeptide species is consistent with experimental W10 wavenumbers. The position of the terminal amine cation near the pyrrole ring is expected to affect the indole ring polarizability. An exoring $\mathrm{C}_{\text {methylene }}-\mathrm{C}_{\alpha}-\mathrm{C}_{\text {carbonyl }}$ symmetric stretch is peculiar to the TrpGly zwitterion, the species with the highest W10 wavenumber. MD simulation shows two hydrogen bonds made by the terminal amine cation, one to C3 of the pyrrole ring, the other to the oxygen of the peptide bond carbonyl (Figure 9(a)). These H-bonds stabilize the orientation of the $\mathrm{C}_{\text {methylene }}-\mathrm{C}_{\alpha}-\mathrm{C}_{\text {carbonyl }}$ segment, which is responsible for the W10 symmetric stretch that is unique to the TrpGly zwitterion.

Nonresonance Raman results for aqueous GlyTrp dipeptide show that $\mathrm{pH}$ titration of only the dissociable group nearest to the indole affects the solvent-sensitive Fermi doublet W7 band ratio [24]. Under our UV resonance Raman conditions, we do not observe changes in the Fermi doublet W7 band ratio for the GlyTrp dipeptide (Table 1). As for the fluorescence emission maximum and the W10 band peak position, the TrpGly zwitterion is the dipeptide species that exhibits an extreme value for the W7 band ratio (Table $1)$.

\section{Conclusions}

The fluorescence emission maxima shifts for TrpGly and GlyTrp zwitterionic and anionic dipeptides are matched by calculated and experimental shifts in the UVRR W10 peak and changes in the W7 Fermi doublet band intensity ratio, $\mathrm{I}\left(1360 \mathrm{~cm}^{-1}\right) / \mathrm{I}\left(1340 \mathrm{~cm}^{-1}\right)$. This spectral correlation has not been previously realized. The W10 vibration of the TrpGly zwitterion has an additional exo-ring symmetric stretch and has the highest energy W10 vibration of all dipeptide species. Ab initio calculations for the $1344 \mathrm{~cm}^{-1}$ band of the W7 Fermi doublet reveal three modes whose intensity or position varies with dipeptide primary sequence and $\mathrm{pH}$. Specifically, calculated $1310 \mathrm{~cm}^{-1}$ and $1320 \mathrm{~cm}^{-1}$ modes are diminished in intensity or absent for all but the TrpGly zwitterion, the species with the lowest W7 band intensity ratio. In nanosecond molecular dynamics simulations of these dipeptides, two conformations predominate: one with the peptide backbone extended and the other with the backbone curled back towards the indole. The significant dihedral angle in these conformations is $\chi^{1}$, which takes on three angles centered at $60^{\circ}, 180^{\circ}$, and $300^{\circ}$. The TrpGly zwitterion is the only species that spends appreciable time in the extended conformation. A significant molecular feature of this conformation is the position of a terminal amine hydrogen $2.44 \AA$ from the pyrrole ring $\mathrm{C}_{3}$. A second terminal amine hydrogen bonds to the peptide carbonyl, securing the alignment of the $\mathrm{C}_{\text {methylene }}-\mathrm{C}_{\alpha}-\mathrm{C}_{\text {carbonyl }}$ of the indole ring. This hydrogen bond reinforcement of the extended backbone may be responsible for the exo-ring $\mathrm{C}_{\text {methylene- }}{ }^{-}$ $\mathrm{C}_{\alpha}-\mathrm{C}_{\text {carbonyl }} \mathrm{W} 10$ symmetric stretch that is peculiar to the TrpGly zwitterion. The effect of the amine cation position on the fluorescence emission maximum for the TrpGly zwitterion is predicted by a Stark effect model [48]. This model predicts a fluorescence emission shift to higher energy when a positive charge is near the pyrrole ring. This blue shift is observed experimentally for the TrpGly zwitterion where MD simulation shows that a hydrogen from the terminal amine cation is positioned $2.44 \AA$ from the indole ring $\mathrm{C}_{3}$. UVRR and fluorescence spectroscopic studies of other tryptophan dipeptides are underway. Similar fluorescence emission shifts have been found for other tryptophan dipeptides, but the specifics of backbone-indole ring interaction are unexplored [21]. With the insight offered by UVRR spectroscopy, molecular dynamics simulation, and employing the Stark effect model, we will continue to map fluorescence emission shifts to specific details of molecular environment for tryptophan.

\section{Acknowledgments}

The authors wish to thank B. Gibney, A. Jarzecki, and M. Kobrak for discussion and suggestions relating to this work. This study was supported by NIH Grant 5 SCZGM09229101.

\section{References}

[1] D. V. Tulumello and C. M. Deber, "Positions of polar amino acids alter interactions between transmembrane segments and detergents," Biochemistry, vol. 50, no. 19, pp. 3928-3935, 2011.

[2] S. P. Laptenok, N. V. Visser, R. Engel et al., "A general approach for detecting folding intermediates from steady-state and 
time-resolved fluorescence of single-tryptophan-containing proteins," Biochemistry, vol. 50, no. 17, pp. 3441-3450, 2011.

[3] K. M. Sanchez, G. Kang, B. Wu, and J. E. Kim, "Tryptophanlipid interactions in membrane protein folding probed by ultraviolet resonance Raman and fluorescence spectroscopy," Biophysical Journal, vol. 100, no. 9, pp. 2121-2130, 2011.

[4] R. Kenoth, R. K. Kamlekar, D. K. Simanshu et al., "Conformational folding and stability of the HET-C2 glycolipid transfer protein fold: does a molten globule-like state regulate activity?" Biochemistry, vol. 50, no. 23, pp. 5163-5171, 2011.

[5] A. R. Molla, S. S. Maity, S. Ghosh, and D. K. Mandal, "Organization and dynamics of tryptophan residues in tetrameric and monomeric soybean agglutinin: studies by steady-state and time-resolved fluorescence, phosphorescence and chemical modification," Biochimie, vol. 91, no. 7, pp. 857-867, 2009.

[6] D. Verbaro, I. Ghosh, W. M. Nau, and R. Schweitzer-Stenner, "Discrepancies between conformational distributions of a polyalanine peptide in solution obtained from molecular dynamics force fields and amide I' band profiles," The Journal of Physical Chemistry B, vol. 114, no. 51, pp. 17201-17208, 2010.

[7] C. P. Moon and K. G. Fleming, "Using tryptophan fluorescence to measure the stability of membrane proteins folded in liposomes," Methods in Enzymology, vol. 492, pp. 189-211, 2011.

[8] D. Ni, J. Zook, D. Klewer, R. Nieman, J. Soll, and P. Fromme, "Isolation, folding and structural investigations of the amino acid transporter OEP16," Protein Expression and Purification, vol. 80, no. 2, pp. 157-168, 2011.

[9] D. A. Kelkar, A. Chaudhuri, S. Haldar, and A. Chattopadhyay, "Exploring tryptophan dynamics in acid-induced molten globule state of bovine $\alpha$-lactalbumin: a wavelength-selective fluorescence approach," European Biophysics Journal, vol. 39, no. 10, pp. 1453-1463, 2010.

[10] T. I. Brelidze, A. E. Carlson, D. R. Davies, L. J. Stewart, and W. N. Zagotta, "Identifying regulators for EAG1 channels with a novel electrophysiology and tryptophan fluorescence based screen," PLoS ONE, vol. 5, no. 9, Article ID e12523, pp. 1-11, 2010.

[11] Q. Chen, M. H. Cheng, Y. Xu, and P. Tang, "Anesthetic binding in a pentameric ligand-gated ion channel: GLIC," Biophysical Journal, vol. 99, no. 6, pp. 1801-1809, 2010.

[12] J. Broos, K. Tveen-Jensen, E. De Waal et al., "The emitting state of tryptophan in proteins with highly blue-shifted fluorescence," Angewandte Chemie, vol. 46, no. 27, pp. 5137-5139, 2007.

[13] E. A. Burstein, N. S. Vedenkina, and M. N. Ivkova, "Fluorescence and the location of tryptophan residues in protein molecules," Photochemistry and Photobiology, vol. 18, no. 4, pp. 263-279, 1973.

[14] Y. Reshetnyak and E. Burstein, "Assignments of the components of the fluorescence spectrum of protein to tryptophan residues based on the properties of their microenvironments in a three dimensional structure," Biophysics, vol. 42, no. 2, pp. 267-274, 1997.

[15] P. L. Muiño and P. R. Callis, "Hybrid simulations of solvation effects on electronic spectra: indoles in water," The Journal of Chemical Physics, vol. 100, no. 6, pp. 4093-4109, 1994.

[16] P. R. Callis and B. K. Burgess, "Tryptophan fluorescence shifts in proteins from hybrid simulations: an electrostatic approach," Journal of Physical Chemistry B, vol. 101, no. 46, pp. 9429-9432, 1997.
[17] J. T. Vivian and P. R. Callis, "Mechanisms of tryptophan fluorescence shifts in proteins," Biophysical Journal, vol. 80, no. 5, pp. 2093-2109, 2001.

[18] T. Miura, H. Takeuchi, and I. Harada, "Tryptophan Raman bands sensitive to hydrogen bonding and side-chain conformation," Journal of Raman Spectroscopy, vol. 20, no. 10, pp. 667-671, 1989.

[19] T. Maruyama and H. Takeuchi, "Effects of hydrogen bonding and side-chain conformation on the Raman bands of tryptophan-2,4,5,6- $\mathrm{d}_{5}$," Journal of Raman Spectroscopy, vol. 26, no. 4, pp. 319-324, 1995.

[20] L. J. Juszczak and R. Z. B. Desamero, "Extension of the tryptophan $\chi 2,1$ dihedral angle-W3 band frequency relationship to a full rotation: correlations and caveats," Biochemistry, vol. 48, no. 12, pp. 2777-2787, 2009.

[21] R. F. Chen, J. R. Knutson, H. Ziffer, and D. Porter, "Fluorescence of tryptophan dipeptides: correlations with the rotamer model," Biochemistry, vol. 30, no. 21, pp. 5184-5195, 1991.

[22] C. Fahlstrom, P. R. Callis, L. Spangler, and G. Gillispie, 64th Northwest Regional Meeting of the American Chemical Society, Tacoma, WA, 2009.

[23] C. Fahlstrom, L. Spangler, G. Gillispie, and P. R. Callis, Joint 65th Northwestern and 22nd Rocky Mountain Regional Meeting of the American Chemical Society, Pullman, WA, 2010.

[24] I. Harada, T. Miura, and H. Takeuchi, "Origin of the doublet at 1360 and $1340 \mathrm{~cm}^{-1}$ in the Raman spectra of tryptophan and related compounds," Spectrochimica Acta A, vol. 42, no. 2-3, pp. 307-312, 1986.

[25] D. E. Schlamadinger, J. E. Gable, and J. E. Kim, "Hydrogen bonding and solvent polarity markers in the UV resonance Raman spectrum of tryptophan: application to membrane proteins," Journal of Physical Chemistry B, vol. 113, no. 44, pp. 14769-14778, 2009.

[26] A. Sanford, R. Bormett, X. Chen et al., "UV resonance Raman spectroscopy using a new CW laser source: convenience and experimental simplicity," Applied Spectroscopy, vol. 47, no. 5, pp. 628-633, 1993.

[27] M. J. Frisch, G. W. Trucks, H. B. Schlegel et al., Gaussian 09 Revision A.02, Gaussian, Inc., Wallingford, Conn, USA, 2009.

[28] A. P. Scott and L. Radom, "Harmonic vibrational frequencies: an evaluation of Hartree-Fock, Møller-Plesset, quadratic configuration interaction, density functional theory, and semiempirical scale factors," Journal of Physical Chemistry, vol. 100, no. 41, pp. 16502-16513, 1996.

[29] B. Hess, C. Kutzner, D. Van Der Spoel, and E. Lindahl, "GROMACS 4: algorithms for highly efficient, load-balanced, and scalable molecular simulation," Journal of Chemical Theory and Computation, vol. 4, no. 3, pp. 435-447, 2008.

[30] W. Weber, P. H. Hünenberger, and J. Andrew McCammon, "Molecular dynamics simulations of a polyalanine octapeptide under Ewald boundary conditions: influence of artificial periodicity on peptide conformation," Journal of Physical Chemistry B, vol. 104, no. 15, pp. 3668-3675, 2000.

[31] P. Mark and L. Nilsson, "Molecular dynamics simulations of the Ala-Pro dipeptide in water: conformational dynamics of trans and cis isomers using different water models," Journal of Physical Chemistry B, vol. 105, no. 33, pp. 8028-8035, 2001.

[32] S. Spörlein, H. Carstens, H. Satzger et al., "Ultrafast spectroscopy reveals subnanosecond peptide conformational dynamics and validates molecular dynamics simulation," Proceedings of the National Academy of Sciences of the United States of America, vol. 99, no. 12, pp. 7998-8002, 2002.

[33] L. L. Laaksonen, gOpenMol 1.31, Center of Scientific Computations, Espoo, Finland, 1999. 
[34] A. Sato, Y. Gao, T. Kitagawa, and Y. Mizutani, "Primary protein response after ligand photodissociation in carbonmonoxy myoglobin," Proceedings of the National Academy of Sciences of the United States of America, vol. 104, no. 23, pp. 9627-9632, 2007.

[35] I. R. Rodriguez-Mendieta, G. R. Spence, C. Gell, S. E. Radford, and D. A. Smith, "Ultraviolet resonance Raman studies reveal the environment of tryptophan and tyrosine residues in the native and partially folded states of the E colicin-binding immunity protein Im7," Biochemistry, vol. 44, no. 9, pp. 33063315, 2005.

[36] M. Ibrahim, M. Kuchinskas, H. Youn et al., "Mechanism of the CO-sensing heme protein CooA: new insights from the truncated heme domain and UVRR spectroscopy," Journal of Inorganic Biochemistry, vol. 101, no. 11-12, pp. 1776-1785, 2007.

[37] Z. Q. Wen and G. J. Thomas, "Ultraviolet-resonance Raman spectroscopy of the filamentous virus Pf3: interactions of Trp 38 specific to the assembled virion subunit," Biochemistry, vol. 39, no. 1, pp. 146-152, 2000.

[38] X. Hu and T. G. Spiro, "Tyrosine and tryptophan structure markers in hemoglobin ultraviolet resonance Raman spectra: mode assignments via subunit-specific isotope labeling of recombinant protein," Biochemistry, vol. 36, no. 50, pp. 1570115712, 1997.

[39] L. J. Juszczak, Z. Y. Zhang, L. Wu, D. S. Gottfried, and D. D. Eads, "Rapid loop dynamics of Yersinia protein tyrosine phosphatases," Biochemistry, vol. 36, no. 8, pp. 2227-2236, 1997.

[40] H. Gallouj, P. Lagant, and G. Vergoten, "A density functional theory-derived force field for 3-ethylindole. Use of the ultraviolet resonance Raman intensities to check the vibrational analysis accuracy," Journal of Raman Spectroscopy, vol. 29, no. 5, pp. 343-351, 1998.

[41] A. Combs, K. McCann, D. Autrey, J. Laane, S. A. Overman, and G. J. Thomas, "Raman signature of the non-hydrogenbonded tryptophan side chain in proteins: experimental and ab initio spectra of 3-methylindole in the gas phase," Journal of Molecular Structure, vol. 735-736, pp. 271-278, 2005.

[42] H. S. Shafaat, B. S. Leigh, M. J. Tauber, and J. E. Kim, "Resonance Raman characterization of a stable tryptophan radical in an azurin mutant," Journal of Physical Chemistry B, vol. 113, no. 1, pp. 382-388, 2009.

[43] S. D. Dieng and J. P. M. Schelvis, "Analysis of measured and calculated Raman spectra of indole, 3-methylindole, and tryptophan on the basis of observed and predicted isotope shifts," Journal of Physical Chemistry A, vol. 114, no. 40, pp. 10897-10905, 2010.

[44] I. Harada and H. Takeuchi, "Raman and ultraviolet resonance Raman spectra of proteins and related compounds," in Spectroscopy of Biological Systems, R. J. H. Clark and R. E. Hester, Eds., vol. 13, pp. 113-175, John Wiley \& Sons, New York, NY, USA, 1986.

[45] L. Jiang and L. Lai, "CH . O O hydrogen bonds at proteinprotein interfaces," Journal of Biological Chemistry, vol. 277, no. 40, pp. 37732-37740, 2002.

[46] S. Scheiner, "Relative strengths of $\mathrm{NH} \cdot \mathrm{O}$ and $\mathrm{CH} \cdot \cdot \mathrm{O}$ hydrogen Bonds between polypeptide chain segments," Journal of Physical Chemistry B, vol. 109, no. 33, pp. 16132-16141, 2005.

[47] J. P. Gallivan and D. A. Dougherty, "Cation- $\pi$ interactions in structural biology," Proceedings of the National Academy of Sciences of the United States of America, vol. 96, no. 17, pp. 9459-9464, 1999.
[48] P. R. Callis and T. Liu, "Quantitative prediction of fluorescence quantum yields for tryptophan in proteins," Journal of Physical Chemistry B, vol. 108, no. 14, pp. 4248-4259, 2004. 

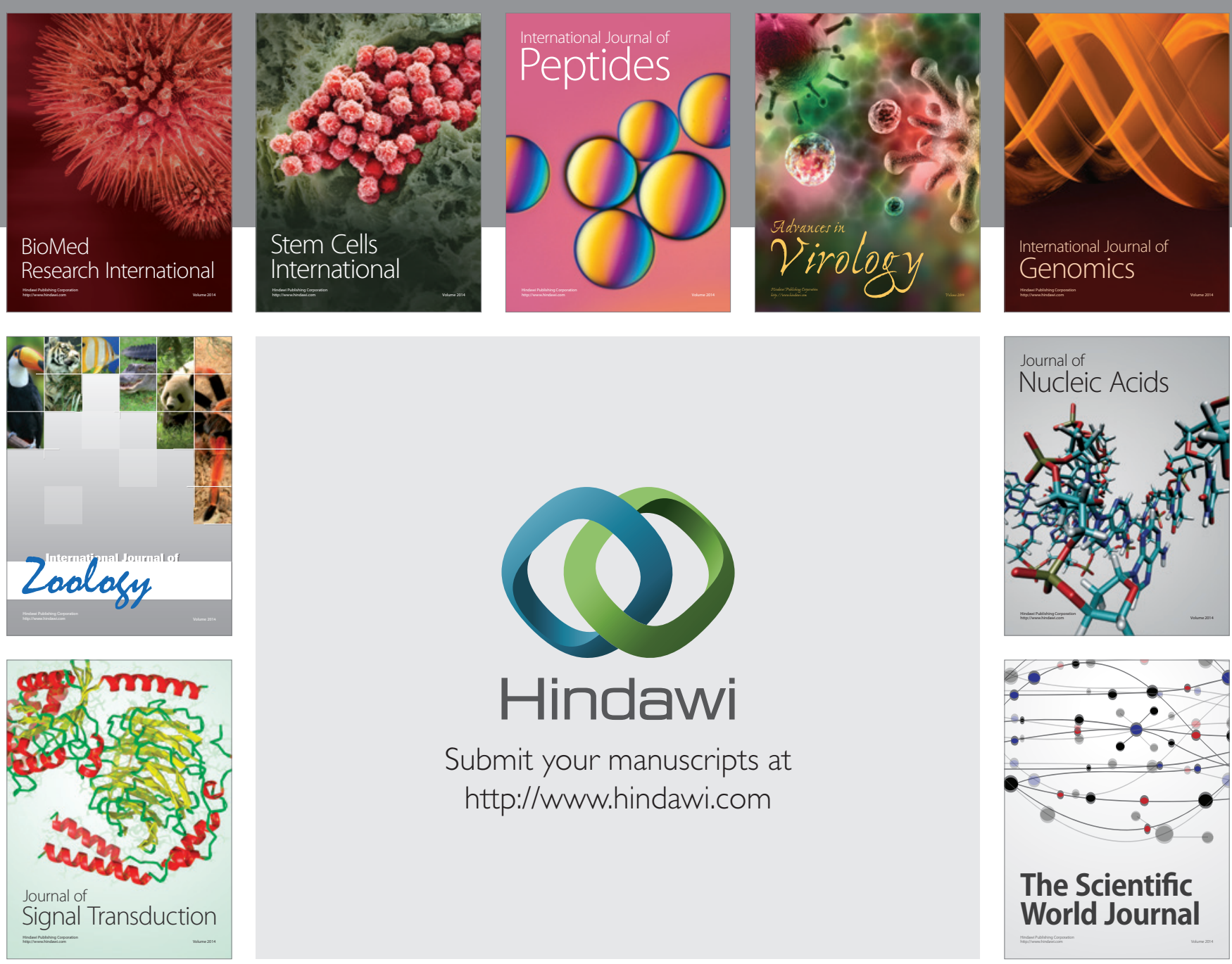

Submit your manuscripts at

http://www.hindawi.com
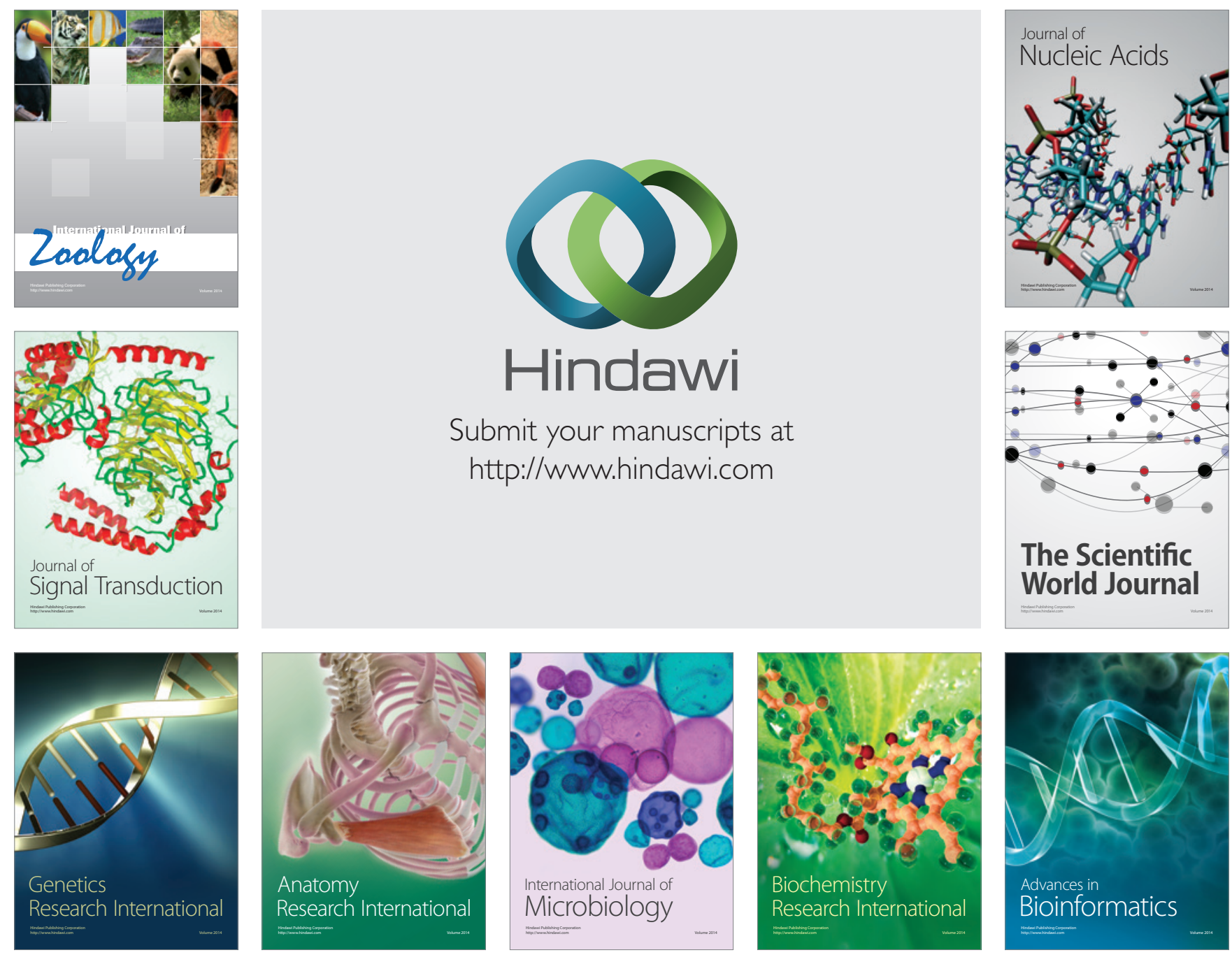

The Scientific World Journal
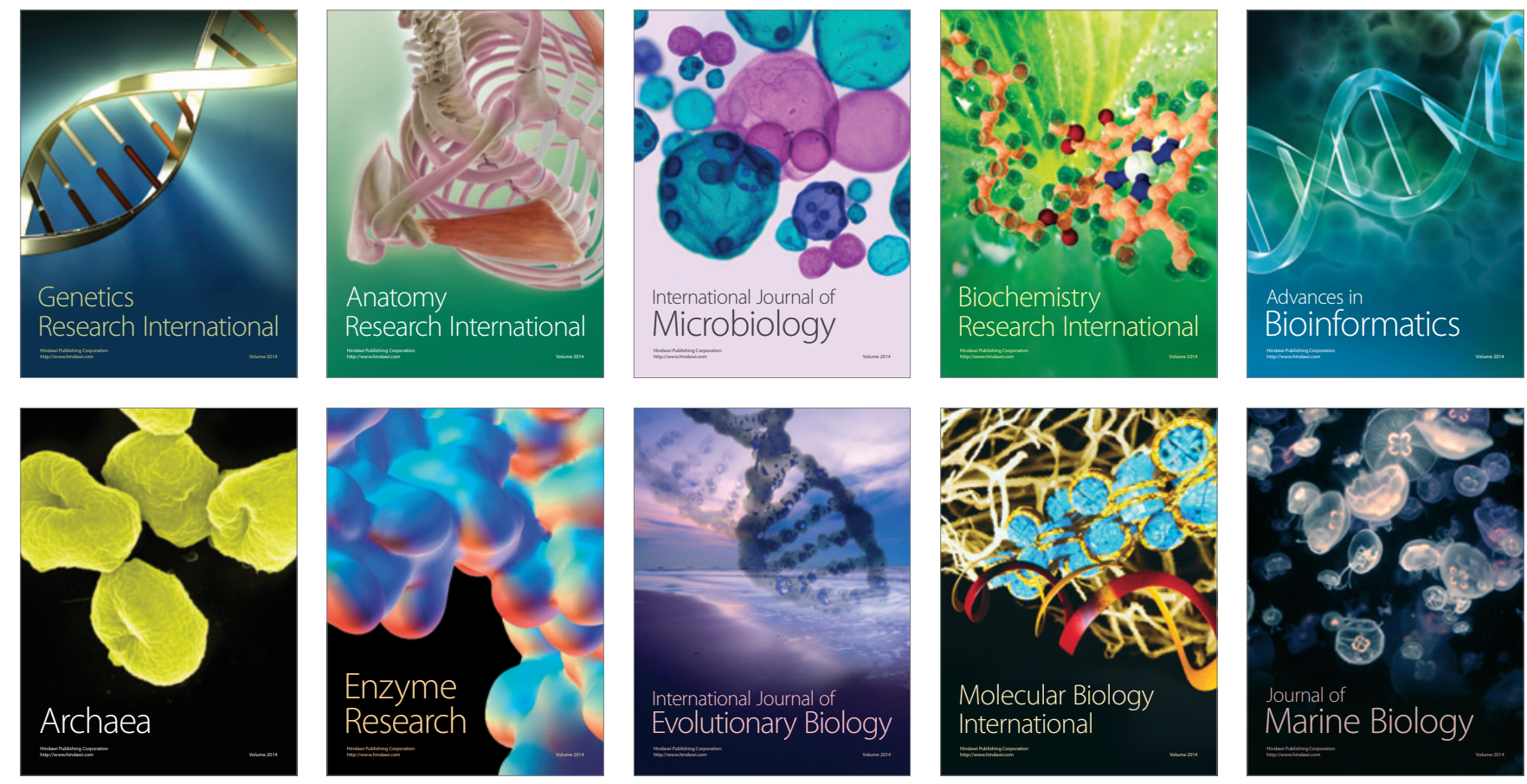